\title{
Effect of Osteoprotegerin and XRCC3 Genes Polymorphisms with the Occurrence of Left Ventricular Hypertrophy in Hypertensive Patients
}

\author{
Hamza M. Kabil, Ahmed Y. Nammour, Al-Shimaa M. Sabry, Amr M. A. Mohammed* \\ Departments of Cardiology, Faculty of Medicine, Benha University, Benha, Egypt \\ Email: dr.hamza_kabil@hotmail.com,dr.ahmednammour@gmail.com,dr.shimaasabry@yahoo.com, *amrdr1992@gmail.com
}

How to cite this paper: Kabil, H.M. Nammour, A.Y., Sabry, A.-S.M. and Mohammed, A.M.A. (2020) Effect of Osteoprotegerin and XRCC3 Genes Polymorphisms with the Occurrence of Left Ventricular Hypertrophy in Hypertensive Patients. World Journal of Cardiovascular Diseases, 10, 78-90.

https://doi.org/10.4236/wjcd.2020.102010

Received: January 14, 2020

Accepted: February 17, 2020

Published: February 20, 2020

Copyright ( 2020 by author(s) and Scientific Research Publishing Inc. This work is licensed under the Creative Commons Attribution International License (CC BY 4.0).

http://creativecommons.org/licenses/by/4.0/

\begin{abstract}
Background: High blood pressure is associated with adverse morphological and functional changes in the cardiovascular system, including left ventricular hypertrophy (LVH). Osteoprotegerin (OPG) is a member of the tumor necrosis factor receptor superfamily of cytokines. X-ray repair cross-complementing protein 3 (XRCC3) is involved in the repair pathway for double-strand breaks (DSBs). We assessed the association of osteoprotegerin and XRCC3 gene polymorphisms with the occurrence of left ventricular hypertrophy in hypertensive patients. Patients and methods: The study included 50 hypertensive patients: 25 with LVH (group A) and 25 without LVH (group B). All cases were subjected to complete history taking and clinical examination. ECG and echocardiography were done. LV mass was calculated to detect the presence or absence of LV hypertrophy. DNA was extracted from blood samples, and then, each DNA sample was amplified in PCRs, to detect osteoprotogrin and XRCC3 gene polymorphisms. Results: Mean age in the cases in group A is 63.12 years and in group B was 58.24 years with statistically significant difference between the two groups. The duration of the disease and SBP revealed statistically significant difference between the two groups. The LV mass index and E/A ratio revealed high statistically significant difference between the two groups. OPG sequence revealed no statistically significant difference between the two groups, but XRCC3 sequence revealed statistically significant difference. The age was a risk factor for LVH. Conclusion: Osteoprotogrin and XRCC3 genes polymorphism mutations may be associated with left ventricular hypertrophy in hypertensive patients.
\end{abstract}

\section{Keywords}

Complications of Hypertension, Left Ventricular Hypertrophy, 


\section{Introduction}

High blood pressure is associated with adverse morphological and functional changes in the cardiovascular system, including left ventricular hypertrophy (LVH) [1] [2]. LVH is regarded as an independent risk factor for cardiovascular morbidity and mortality [3] [4] [5] [6] [7]. Many factors (blood pressure level, duration of hypertension, age, obesity, diet, and pharmacologic treatment) may influence the occurrence and degree of LVH [8] [9]. In addition, the genetic factors are related to LVH as well [10] [11] [12]. A number of candidate genes responsible for LVH have been studied in different ethnic populations [13] [14] [15].

Osteoprotegerin (OPG) is a member of the tumor necrosis factor receptor superfamily of cytokines and a soluble receptor for the receptor activator for nuclear factor- $\kappa B$ ligand [16]. Association of serum OPG with left ventricular mass was reported in African-American adults with hypertension and in the general population [17] [18]. Human OPG gene located on chromosome 8 represents a single-copy gene with 5 exons spanning $29 \mathrm{~kb}$ of the human genome [19].

Several polymorphisms at the OPG promoter have been associated with vascular morphology and function in different populations. However, the role of OPG gene polymorphisms and serum OPG level in the development of cardiac remodeling, such as LVH development under hypertensive condition, has not been addressed. In the present study, we enrolled patients with essential hypertension (EH) to investigate the possible association between OPG genetic polymorphisms and LVH occurrence [20].

$\mathrm{X}$-ray repair cross-complementing protein 3 (XRCC3) participates in homologous recombination and is involved in the repair pathway for double-strand breaks (DSBs). XRCC3 deficiency results in a defect in recombination and results in increased endoreduplication. Endoreduplication is the replication of the nuclear genome without subsequent cell division; this process leads to polyploidy and an increase in cell size [21].

The study aimed to assess the association of osteoprotegerin and XRCC3 genes polymorphisms with the occurrence of left ventricular hypertrophy in hypertensive patients.

\section{Patients and Methods}

This is a case- control study conducted to assess the association of osteoprotegerin and XRCC3 genes polymorphisms with the occurrence of left ventricular hypertrophy in hypertensive patients. This study was conducted at the Cardiology Department, Benha University Hospital, Egypt.

The study included 50 cases that were divided into two groups each of 25 
cases as follows: hypertensive patients with LVH (group I) and hypertensive patients without LVH (group II).

\section{Inclusion criteria:}

Patients with essential hypertension without other comorbidities.

\section{Exclusion criteria:}

1) Patients who have secondary hypertension.

2) Patients with DM.

3) Patients with chronic kidney disease.

4) Patients with valvular or congenital heart disease.

5) Patients with cardiomyopathy.

\section{Methods:}

1) Complete history taking:

- Demographic data.

- History of the current disease.

- Medical and surgical history.

- History of drug intake.

2) Clinical examination:

- Pulse.

- Blood pressure.

- Height, weight, waist circumference, body mass index (BMI) calculation.

- Local examination to assess sound, apical impulse and jugular venous pulse.

3) ECG: for assessment of signs of LVH.

4) Echocardiography.

5) Determination of LV mass: The calculation of the LV mass was done to detect the presence or absence of LV hypertrophy according to the following law: $\mathrm{LV}$ mass $=0.8 \times(1.04 \times(($ LVIDd + PWTd + SWTd $) 3-($ LVIDd $) 3))=0.6 \mathrm{~g}$.

6) PCR- detection of the polymorphism of the gene (XRCC3).

7) PCR- detection of the polymorphism of the osteoprotogringene (OPG).

\section{Statistical analysis}

The collected data were coded, processed and analyzed using the SPSS (Statistical Package for Social Sciences) version 22 for Windows ${ }^{\circledR}$ (SPSS Inc, Chicago, IL, USA). Qualitative data was presented as number (frequency) and Percent. Comparison between groups was done by Chi-Square test $\left(\chi^{2}\right)$. Quantitative data was tested for normality by Kolmogorov-Smirnov test. Normally distributed data was presented as mean $\pm \mathrm{SD}$. Student $\mathrm{t}$-test was used to compare between two groups (expressed as t). Non-parametric data was presented as median (min max). Mann-Whitney test (expressed as $\mathrm{z}$ ) was used for comparison between groups. Logistic regression analysis was used for univariate and multivariate analysis for prediction of LVH. Receiver operator curve was used to analyze the predictive ability of quantitative variable (LV mass index) to differentiate cases with and without LVH. $\mathrm{P}<0.05$ was considered to be statistically significant.

\section{Results}

The mean in the cases in group A is $63.12 \pm 7.23$ years and in group B was 58.24 
\pm 7.16 years with statistically significant difference between the two groups $(\mathrm{p}=$ $0.025)$. There were $52 \%$ males and $48 \%$ females in group $A$ and $64 \%$ males and $36 \%$ females in group B with no statistically significant difference between the two groups (Table 1 ).

There were statistically significant differences between the two groups regarding SBP, prominent a wave and second sound split and high statistically significant differences regarding forcible apex and fourth heart sound (Table 2).

The mean LV mass index was $131.52 \pm 11.82 \mathrm{gm} / \mathrm{m}^{2}$ in group $A$ and it was $84.63 \pm 14.87 \mathrm{gm} / \mathrm{m}^{2}$ in group B with high statistically significant difference between the two groups $(\mathrm{p}<0.001)$ (Table 3$)$.

There were statistically significant differences between the two groups regarding mean E/A ratio and diastolic dysfunction grade. The mean PWEDd, IVSDd and LV mass (gram) also revealed high statistically significant difference between the two groups being higher in group A (Table 4).

The analysis of OPG in the two study groups is shown in Table 5, the CC sequence was present in $20 \%$ of cases in group A and in $32 \%$ of cases in group B, the CG sequence was present in $44 \%$ of cases in group A and $48 \%$ of cases in group B while the GG sequence were found in 36\% of cases in group A and $20 \%$ of cases in group B with no statistically significant difference between the two groups $(\mathrm{p}=0.387)$.

The analysis of XRCC3 in the two study groups is shown in Table 6, the Thr/Met base pair was present in $48 \%$ of cases in group $\mathrm{A}$ and in $16 \%$ of cases in group B while the Thr/Thr base pairs was present in $52 \%$ of cases in group A and $84 \%$ of cases in group B with statistically significant difference between the two groups $(\mathrm{p}=0.015)$.

With the univariate risk analysis, age, duration of the disease, prominent a wave, EA ratio, diastolic dysfunction grade, PWEDd, IVSDd, LV mass and LV

Table 1. Analysis of demographic data in the two study groups.

\begin{tabular}{|c|c|c|c|}
\hline & \multicolumn{2}{|c|}{ Groups } & \multirow[b]{2}{*}{$\begin{array}{c}\text { Test of } \\
\text { significance }\end{array}$} \\
\hline & $\begin{array}{c}\text { Group A } \\
\text { HTN with LVH } \\
(\mathrm{N}=25)\end{array}$ & $\begin{array}{c}\text { Group B } \\
\text { HTN without LVH } \\
(\mathrm{N}=25)\end{array}$ & \\
\hline Age (years) & $63.12 \pm 7.23$ & $58.24 \pm 7.16$ & $\mathrm{p}=0.025^{\star}$ \\
\hline \multirow{2}{*}{ Gender } & $13(52 \%)$ & $16(64 \%)$ & \multirow{2}{*}{$\mathrm{p}=0.342$} \\
\hline & $12(48 \%)$ & $9(36 \%)$ & \\
\hline Height & $171.4 \pm 8.01$ & $171 \pm 7.65$ & $\mathrm{p}=0.986$ \\
\hline Weight & $79.24 \pm 12.18$ & $82.08 \pm 14.54$ & $\mathrm{p}=0.458$ \\
\hline Waist-circumference & $88.28 \pm 6.87$ & $87.76 \pm 6.69$ & $\mathrm{p}=0.787$ \\
\hline BMI & $26.97 \pm 2.88$ & $27.93 \pm 3.52$ & $\mathrm{p}=0.296$ \\
\hline BSA & $1.93 \pm 0.19$ & $1.97 \pm 0.21$ & $\mathrm{p}=0.552$ \\
\hline
\end{tabular}

P: probability. Continuous data expressed as mean \pm SD. Categorical data expressed as Number $(\%) .^{*}$ : statistically significant when $(\mathrm{p}<0.05)$. 
Table 2. Analysis of clinical data in the two study groups.

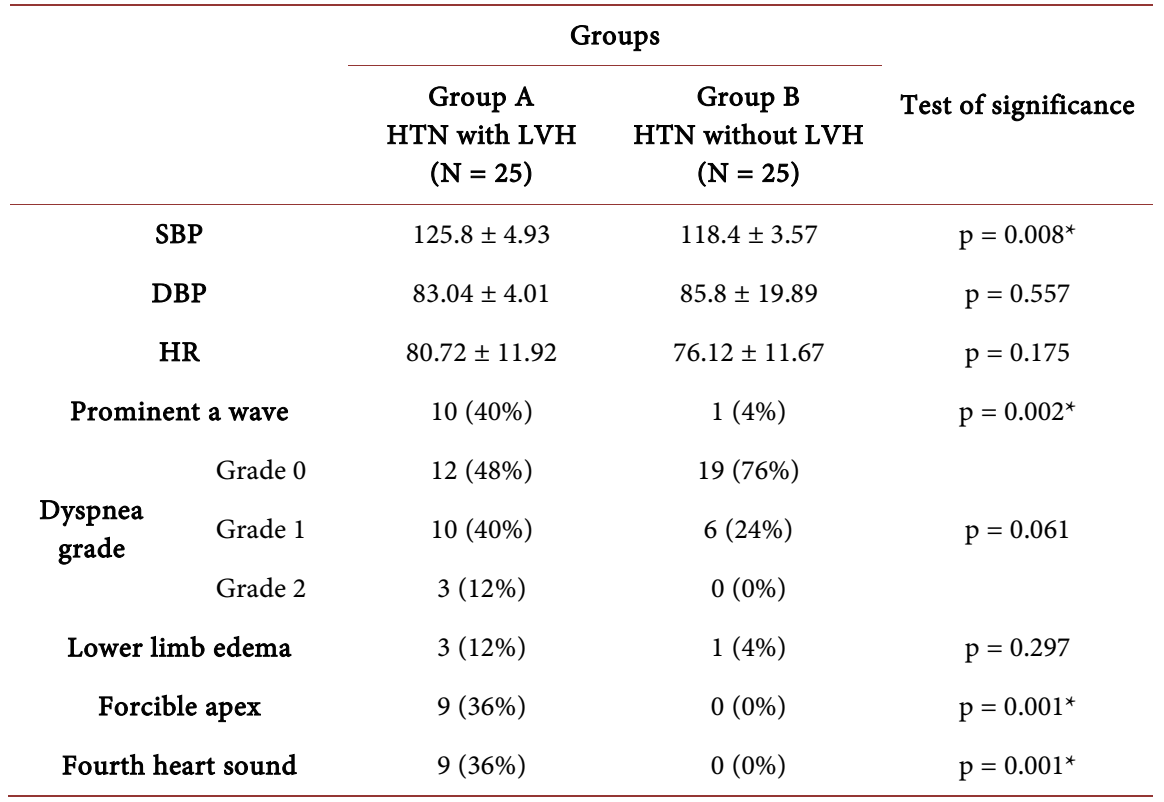

Table 3. LV mass index in the two study groups.

\begin{tabular}{cccc}
\hline & \multicolumn{2}{c}{ Groups } & \\
\cline { 2 - 3 } & Group A & Group B & Test of \\
& HTN with LVH & HTN without LVH & significance \\
& $(\mathrm{N}=25)$ & $(\mathrm{N}=25)$ & \\
\hline LV mass index $\left(\mathrm{gm} / \mathrm{m}^{2}\right)$ & $131.52 \pm 11.82$ & $84.63 \pm 14.87$ & $\mathrm{p}<0.001^{*}$ \\
\hline
\end{tabular}

Table 4. Analysis of echocardiography in the two study groups.

\begin{tabular}{|c|c|c|c|c|}
\hline & & \multicolumn{2}{|c|}{ Groups } & \multirow[b]{2}{*}{$\begin{array}{c}\text { Test of } \\
\text { significance }\end{array}$} \\
\hline & & $\begin{array}{c}\text { Group A } \\
\text { HTN with LVH } \\
(\mathrm{N}=25)\end{array}$ & $\begin{array}{c}\text { Group B } \\
\text { HTN without LVH } \\
(\mathrm{N}=25)\end{array}$ & \\
\hline \multicolumn{2}{|c|}{$\mathrm{EF}(\%)$} & $68.88 \pm 6.54$ & $67.36 \pm 6.54$ & $\mathrm{p}=0.415$ \\
\hline \multicolumn{2}{|c|}{ FS (\%) } & $39.04 \pm 5.27$ & $37.49 \pm 5.04$ & $\mathrm{p}=0.291$ \\
\hline \multicolumn{2}{|c|}{ E/A ratio } & $0.79 \pm 0.22$ & $1.38 \pm 0.29$ & $\mathrm{p}<0.001^{*}$ \\
\hline \multirow{3}{*}{$\begin{array}{l}\text { Diastolic } \\
\text { dysfunction } \\
\text { grade }\end{array}$} & Grade 0 & $4(16 \%)$ & $22(88 \%)$ & \\
\hline & Grade 1 & $21(84 \%)$ & $0(0 \%)$ & $\mathrm{p}<0.001^{\star}$ \\
\hline & Grade 2 & $0(0 \%)$ & $3(12 \%)$ & \\
\hline \multicolumn{2}{|c|}{ LVEDD } & $5.02 \pm 0.51$ & $4.76 \pm 0.55$ & $p=0.091$ \\
\hline \multicolumn{2}{|c|}{ PWEDd } & $1.26 \pm 0.12$ & $0.99 \pm 0.11$ & $\mathrm{p}<0.001^{\star}$ \\
\hline \multicolumn{2}{|c|}{ IVSDd } & $1.28 \pm 0.13$ & $0.97 \pm 0.11$ & $\mathrm{p}<0.001^{\star}$ \\
\hline \multicolumn{2}{|c|}{ LV mass (gram) } & $255.45 \pm 39.17$ & $166.68 \pm 36.37$ & $\mathrm{p}<0.001^{\star}$ \\
\hline
\end{tabular}

P: probability. Continuous data expressed as mean \pm SD. Categorical data expressed as Number (\%). *: statistically significant when $(\mathrm{p}<0.05)$ EF: ejection fraction. FS: fraction shortening. LVEDD: left ventricular end diastolic diameter. 
Table 5. Analysis of osteoprotegerin in the two study groups.

\begin{tabular}{|c|c|c|c|c|c|}
\hline & & \multicolumn{2}{|c|}{ Groups } & \multirow[b]{2}{*}{$\begin{array}{c}\text { OR } \\
(95 \% \mathrm{CI})\end{array}$} & \multirow[b]{2}{*}{$\begin{array}{c}\text { Test of } \\
\text { significance }\end{array}$} \\
\hline & & $\begin{array}{c}\text { Group A } \\
\text { HTN with LVH } \\
(\mathrm{N}=25)\end{array}$ & $\begin{array}{c}\text { Group B } \\
\text { HTN without LVH } \\
(\mathrm{N}=25)\end{array}$ & & \\
\hline \multirow{3}{*}{ OPG } & $\mathrm{CC}$ & $5(20 \%)$ & $8(32 \%)$ & & \multirow[b]{2}{*}{0.78} \\
\hline & CG & $11(44 \%)$ & $12(48 \%)$ & $0.97(0.62-1.25)$ & \\
\hline & GG & $9(36 \%)$ & $5(20 \%)$ & $1.48(0.75-1.89)$ & 0.21 \\
\hline \multirow{2}{*}{ alleles } & G & $29(58 \%)$ & $22(44 \%)$ & \multirow{2}{*}{$1.22(0.35-2.13)$} & \multirow[b]{2}{*}{0.16} \\
\hline & $\mathrm{C}$ & $21(42 \%)$ & $28(56 \%)$ & & \\
\hline
\end{tabular}

P: probability. Categorical data expressed as Number (\%). $\chi^{2}=$ Chi-square test. OPG: Osteoprotegerin gene.

Table 6. Analysis of XRCC3 in the two study groups.

\begin{tabular}{|c|c|c|c|c|c|}
\hline & & \multicolumn{2}{|c|}{ Groups } & \multirow[b]{2}{*}{$\begin{array}{c}\text { OR } \\
(95 \% \mathrm{CI})\end{array}$} & \multirow[b]{2}{*}{$\begin{array}{c}\text { Test of } \\
\text { significance }\end{array}$} \\
\hline & & $\begin{array}{c}\text { Group A } \\
\text { HTN with LVH } \\
\quad(\mathrm{N}=25)\end{array}$ & $\begin{array}{c}\text { Group B } \\
\text { HTN without LVH } \\
(\mathrm{N}=25)\end{array}$ & & \\
\hline \multirow{2}{*}{ XRCC3 } & Thr/Met & $12(48 \%)$ & $4(16 \%)$ & & \multirow{2}{*}{$\mathrm{p}=0.015^{\star}$} \\
\hline & Thr/Thr & $13(52 \%)$ & $21(84 \%)$ & $2.86(1.98-3.85)$ & \\
\hline \multirow{2}{*}{ Alleles } & Thr & $38(76 \%)$ & 46 (92\%) & \multirow{2}{*}{$3.22(1.13-5.35)$} & \multirow{2}{*}{$0.03^{*}$} \\
\hline & Met & $12(24 \%)$ & $4(8 \%)$ & & \\
\hline
\end{tabular}

P: probability. Categorical data expressed as Number $(\%) \cdot \chi^{2}=$ Chi-square test. ${ }^{*}$ : significant when $(\mathrm{p}<$ $0.05)$.

mass index were significant predictors of LVH. With multivariate regression analysis, smoking, E/A ration, PWEDd and LV mass were independent risk factors for LVH (Table 7).

\section{Discussion}

Hypertension, coronary heart disease, valvular heart disease, cardiomyopathy and congenital heart disease are the main causes of heart failure. Hypertension (HTN) is a leading cause of death and morbidity worldwide. The burden and prevalence of the disease is increasing globally [22].

In response to these cardiovascular insults, the left ventricle (LV) compensates by either hypertrophy or dilatation to preserve and maintain cardiac pump performance. Left ventricular hypertrophy (LVH) secondary to arterial hypertension is a complex cardiac phenotype resulting from the response of myocyte and non-myocyte components to mechanical and neuro-humoral stimuli [23]. LVH and increased LV mass (LVM) are risk factors of coronary artery disease, congestive heart disease and stroke [24].

Bella and Göring [11] have demonstrated that LVH is mediated by the mechanical stress of pressure overload, neurohormonal factors, and various genetic factors that independently exert trophic effects on myocytes and non-myocytes in the heart. 
Table 7. Univariate and multivariate analysis of predictors of LVH.

\begin{tabular}{|c|c|c|c|c|}
\hline \multirow{2}{*}{ Variables } & \multirow{2}{*}{ Univariate analysis } & \multicolumn{3}{|c|}{ Multivariate analysis } \\
\hline & & B & $95 \% \mathrm{CI}$ & $P$ value \\
\hline Age & $0.031^{*}$ & 0.528 & $0.398-1.05$ & 0.362 \\
\hline Gender & 0.391 & & & \\
\hline Duration of the disease & $0.012^{\star}$ & & & \\
\hline Smoking & $<0.001^{*}$ & 1.824 & $1.273-2.982$ & $0.043^{*}$ \\
\hline SBP & 0.071 & & & \\
\hline DBP & 0.618 & & & \\
\hline HR & 0.128 & & & \\
\hline Prominent a wave & $0.011^{*}$ & 1.517 & $1.241-2.28$ & 0.054 \\
\hline Grade of dyspnea & 0.278 & & & \\
\hline Lower limb edema & 0.999 & & & \\
\hline Forcible apex & 0.999 & & & \\
\hline Fourth sound & 0.999 & & & \\
\hline RBS & 0.152 & & & \\
\hline Creatinine & 0.408 & & & \\
\hline Sokolow index & 0.998 & & & \\
\hline Height & 0.985 & & & \\
\hline Weight & 0.451 & & & \\
\hline Waist circumference & 0.782 & & & \\
\hline BMI & 0.296 & & & \\
\hline BSA & 0.544 & & & \\
\hline OPG alleles & 0.16 & & & \\
\hline XRCC3 alleles & $0.03^{*}$ & 1.68 & $1.13-2.97$ & $0.04^{*}$ \\
\hline
\end{tabular}

Genome-wide association studies (GWAS) have identified several single nucleotide polymorphisms (SNPs) associated with echocardiography LVH [25]. Osteoprotegerin (OPG) is a member of the tumor necrosis factor receptor superfamily of cytokines and a soluble receptor for the receptor activator for nuclear factor-kB ligand [16]. The association of serum OPG with left ventricular mass was reported in African-American adults with hypertension and in the general population. X-ray repair cross-complementing protein 3 (XRCC3) participates in homologous recombination and is involved in the repair pathway for double-strand breaks (DSBs) [26].

The aim of this study is to assess the association of osteoprotegerin and XRCC3 genes polymorphisms with the occurrence of left ventricular hypertrophy in hypertensive patients. The study included 50 cases that were divided into two groups each of 25 cases as follows; Group A: hypertensive patients with LVH 
and Group B: Hypertensive patients without LVH.

Another study conducted by Ariyandy et al. [27] aimed to determine the impact of the XRCC3 polymorphism on the incidence of hypertension-induced left ventricular hypertrophy (LVH). The study included 77 hypertensive patients who are maintained on HD.

Another study was conducted by Shen et al. [28] to investigate the role of osteoprotegerin (OPG) in left ventricular hypertrophy (LVH) development in patients with essential hypertension (EH). A total of 1092 patients diagnosed with EH were recruited. The LVHs were determined and OPG gene polymorphisms were genotyped [28].

In this study, the mean in the cases in group $A$ is $63.12 \pm 7.23$ years and in group B was $58.24 \pm 7.16$ years with statistically significant difference between the two groups ( $\mathrm{p}=0.025$ ). This partially agreed with Bahramali et al. [29] who showed that the mean age in cases with $\mathrm{LVH}$ was more than in cases without LVH $(63.3 \pm 12.01$ years vs $61.70 \pm 13.26$ years respectively), but this difference didn't reveal a statistically significance.

In this study, males were affected more than females; there were $52 \%$ males and $48 \%$ females in group A and $64 \%$ males and $36 \%$ females in group B with no statistically significant difference between the two groups. This came in agreement with Ariyandy et al. [27] who reported in their study that males were more than females in the two study groups (18/8 in LVH group and 34/17 in cases without LVH) with no statistically significant difference between the two groups. However, in a study by Bahramali et al. [29], there was high prevalence of females over males (124 females vs 52 males) in the whole study with high statistically significant difference between the two groups.

The median duration of the disease in group A was 5 years with range between 2 to 12 years while in group B it was 4 years with range between 2 to 8 years, with statistically significant difference between the two groups $(\mathrm{p}=0.004)$. This came in contrast to Shen et al. [28] who showed no significant difference in the mean duration of HTN in the groups with or without HTN.

There was no significant difference between the two study groups in the mean height, weight, waist-circumference, BMI and BSA between the two study groups. This agreed with Bahramali et al. [29] as they revealed no significant difference in the mean BMI in cases with and without LVH. This came in contrast with Ariyandy et al. who showed that there was a statistically significant difference in the mean BMI in the cases with and without LVH; being higher in the LVH cases $(\mathrm{p}<0.001)$.

In this study, no cases in the two groups had previous history of CAD, DM, CKD or OSA. In the contrast, Bahramali et al. [29] showed that DM was a common associated disease in both cases with and without HTN that was detected in about $42 \%$ of the cases within the study.

Also in this study, The group of cases with LVH showed higher prevalence of smoking as compared to the group without LVH ( $48 \%$ vs $16 \%$ respectively) ( $\mathrm{p}<$ 
0.001). This came in accordance with Shen et al. [28] who showed statistically significant difference between the group with LVH and without LVH in the incidence of smoking (59.9\% vs $45.6 \%$ ). No significant difference was reported by Bahramali et al. [29] regarding the prevalence of smoking in the two groups included in their study.

In this study, there was no statistically significant difference between the two study groups regarding the use of different drugs; Beta blockers (56\% vs $60 \%$ ), ACEIs ( $48 \%$ vs $40 \%$ ), CCB (12\% vs $24 \%$ ), ARB (16\% vs $28 \%$ ), Diuretics ( $24 \%$ vs $44 \%$ ), Alpha blockers (4\% vs $0 \%$ ) in the groups with and without LVH respectively. This came in accordance with Shen et al. [28] who showed no statistically significant difference between the two groups with and without the HTN treatment protocol, with beta blockers as the most commonly used drugs followed by ACEIs.

The mean SBP in group A was $125.8 \pm 4.93 \mathrm{mmHg}$ and in group B it was $122.4 \pm 3.57 \mathrm{mmHg}$ with statistically significant difference between the two groups $(\mathrm{p}=0.008)$. In another study, the mean SBP in the cases with LVH was $149.7 \pm 10.2 \mathrm{mmHg}$ and in the cases without LVH was $145.2 \pm 8.8$, with statistically significant difference between the two groups $(p=0.049)$ [28]. However, Ariyandy et al. [27] reported no statistically significant difference in the mean SBP between the cases with and without LVH, although they reported that it was higher in cases with LVH. It could be explained by the fact that poor glycemic control is usually associated with HTN or due to the state of cardiac affection.

In this study, all of DBP, HR, grade of dyspnea and lower limb edema didn't reveal statistically significant difference between the two groups. This came in agreement with some studies that revealed no significant difference in the mean DBP between the two groups with or without LVH [27] [28] [29].

The mean RBS and serum creatinine levels in the two study groups didn't reveal significant difference between the two groups. This came in accordance with the results reported by Shen et al. [28] who showed no statistically significant difference between the two groups with and without LVH.

The mean LV mass index was $131.52 \pm 11.82 \mathrm{gm} / \mathrm{m}^{2}$ in group A and it was $84.63 \pm 14.87 \mathrm{gm} / \mathrm{m}^{2}$ in group B with high statistically significant difference between the two groups $(\mathrm{p}<0.001)$. This came in accordance with Bahramoli et al. [29] who showed that the mean LV mass index in the group with LVH was $129.49 \pm 29.69 \mathrm{gm} / \mathrm{m}^{2}$ and in the group without LVH was $80.34 \pm 19.05 \mathrm{gm} / \mathrm{m}^{2}$ with high statistically significant difference between the two groups $(\mathrm{p}<0.001)$.

In this study, the mean EF in cases without $\mathrm{LVH}$ was $67.36 \% \pm 6.54 \%$ and in cases with $\mathrm{LVH}$ was $68.88 \% \pm 6.54 \%$ with no significant difference between the two groups $(\mathrm{p}=0.66)$. This came in agreement with Ariyandy et al. [27] who showed that the mean EF in cases without $\mathrm{LVH}$ was $64.0 \% \pm 12 \%$ and in cases with $\mathrm{LVH}$ was $65.7 \% \pm 9.2 \%$ with no significant difference between the two groups.

The mean $\mathrm{E} / \mathrm{A}$ ratio in group $\mathrm{A}$ was $0.79 \pm 0.22$ and in group $\mathrm{B}$ it was $1.38 \pm$ 
0.29 with high statistically significant difference between the two groups ( $\mathrm{p}<$ 0.001). This came in disagreement with Bahramoli et al. [29] who showed no statistically significant difference in the E/A in the cases with and without LVH $(\mathrm{p}=0.17)$.

The mean PWEDd, IVSDd and LV mass (gram) also revealed high statistically significant difference between the two groups $(\mathrm{p}<0.001)$ being higher in group A. This came in accordance with Bahramoli et al. [29] who showed that there was statistically significant difference in each of the following IVS, LVPW and LVEDD being significantly higher in the cases with LVH ( $\mathrm{p}<0.001)$. However, Ariyandy et al. [27] didn't reveal any significant difference in the mean values of LV end-diastolic dimension and LV end-systolic dimension between cases with and without LVH ( $\mathrm{p}=0.52$ and 0.97 respectively).

In this study, with the analysis of OPG gene sequence, the CC sequence was present in $20 \%$ of cases in group A and in $32 \%$ of cases in group B, the CG sequence was present in $44 \%$ of cases in group A and $48 \%$ of cases in group B while the GG sequence were found in $36 \%$ of cases in group A and $20 \%$ of cases in group B with no statistically significant difference between the two groups ( $\mathrm{p}$ $=0.387$ ).

In another study, Genotype frequencies of OPG polymorphisms in LVH +ve and LVH - ve showed that the genotype and the allele frequencies of $163 \mathrm{~A}>\mathrm{G}$ and $245 \mathrm{~T}>\mathrm{G}$ were not significantly different between LVH +ve and LVH -ve groups (all $\mathrm{P}>0.05$ ). However, the genotypes and allele frequency of $1181 \mathrm{G}>\mathrm{C}$ were significantly different between the 2 groups. $\mathrm{LVH}+$ ve patients had a markedly lower CC genotype than LVH -ve patients $(18.06 \%$ vs $31.12 \%$, global P < 0.001 ). The 1181GG genotype as reference, multivariate logistic regression analysis showed that the 1181CC genotype carriers had a markedly lower chance to develop LVH [28].

Of all genetic variants, the polymorphism at $1181 \mathrm{G}>\mathrm{C}$ locus seems to be more associated with cardiovascular disease than the others. A study in Polish population revealed carriers of the homozygous CC of 1181 OPG gene were shown to have normal coronary arteries more frequently when compared with heterozygotes for CG or homozygotes for GG, but not $209 \mathrm{C} / \mathrm{T}$ and $245 \mathrm{C} / \mathrm{TC}$ polymorphisms [30]. However, another study in Korean population failed to show a significant association between OPG and RANK polymorphisms and acute coronary syndrome occurrence [31].

Regarding the analysis of XRCC 3 sequence in the two study groups in this study, the Thr/Met genotype frequency was present in $48 \%$ of cases in group A and in $16 \%$ of cases in group B while the $\mathrm{Thr} / \mathrm{Thr}$ genotype frequency was present in $52 \%$ of cases in group A and $84 \%$ of cases in group B with statistically significant difference between the two groups $(\mathrm{p}=0.015)$.

Similar results were reported by Ariyandyet al. [27], the Thr/Met genotype frequency was present in $13.7 \%$ of cases in group without LVH and in $42.3 \%$ of cases in group with LVH while the Thr/Thr genotype frequency was present in 
$86.3 \%$ of cases in group without LVH and $57.7 \%$ of cases in group with LVH with statistically significant difference between the two groups.

In this study, with univariate regression analysis, the age was shown as risk factor for LVH and that wasn't revealed by using the multivariate analysis. A report from the Framingham Heart Study showed that increased LV mass strongly predicted all-cause and cardiac mortality and coronary heart disease events in adults over 40 years, independently of conventional risk factors [32].

\section{Conclusion}

Osteoprotogrin and XRCC3 genes polymorphisms mutation may be associated with left ventricular hypertrophy in hypertensive patients.

\section{Conflicts of Interest}

The authors declare no conflicts of interest regarding the publication of this paper.

\section{References}

[1] Nielsen, O.W. and Sajadieh, A. (2007) Diagnosing Left Ventricular Hypertrophy in Arterial Hypertension. BMJ, 335, 681-682.

https://doi.org/10.1136/bmj.39344.470718.BE

[2] Brady, T.M., Fivush, B., Flynn, J.T., et al. (2008) Ability of Blood Pressure to Predict Left Ventricular Hypertrophy in Children with Primary Hypertension. The Journal of Pediatrics, 152, 73-78. https://doi.org/10.1016/j.jpeds.2007.05.053

[3] Zhan, S., Liu, M., Yao, W., et al. (2002) Prevalence and Relevant Factors on Echocardiographic Left Ventricular Hypertrophy among Community-Based Hypertensive Patients in Shanghai. Chinese Journal of Epidemiology, 23, 182-185.

[4] Mancia, G., Bombelli, M., Facchetti, R., et al. (2008) Long-Term Risk of Diabetes, Hypertension and Left Ventricular Hypertrophy Associated with the Metabolic Syndrome in a General Population. Journal of Hypertension, 26, 1602-1611. https://doi.org/10.1097/HJH.0b013e328302f10d

[5] Petrovic, D. and Stojimirovic, B. (2008) Left Ventricular Hypertrophy in Patients Treated with Regular Hemodialyses. Medicinski Pregled, 61, 369-374. https://doi.org/10.2298/MPNS0808369P

[6] Kaplinsky, E. (1994) Significance of Left Ventricular Hypertrophy in Cardiovascular Morbidity and Mortality. Cardiovascular Drugs and Therapy, 8, 549-556. https://doi.org/10.1007/BF00877223

[7] Tovillas-Moran, F.J., Vilaplana-Cosculluela, M., Zabaleta-del-Olmo, E., et al. (2010) Cardiovascular Morbidity and Mortality and Electrocardiographic Criteria of Left Ventricular Hypertrophy in Hypertensive Patients Treated in Primary Care. Medicina Clínica, 135, 397-401.

[8] Ozawa, M., Tamura, K., Okano, Y., et al. (2009) Blood Pressure Variability as Well as Blood Pressure Level Is Important for Left Ventricular Hypertrophy and Brachialankle Pulse Wave Velocity in Hypertensives. Clinical and Experimental Hypertension, 31, 669-679. https://doi.org/10.3109/10641960903407033

[9] Schirmer, H., Lunde, P. and Rasmussen, K. (1999) Prevalence of Left Ventricular Hypertrophy in a General Population: The Tromso Study. European Heart Journal, 
20, 429-438. https://doi.org/10.1053/euhj.1998.1314

[10] Castro, M.G., Rodriguez-Pascual, F., Magan-Marchal, N., et al. (2007) Screening of the Endothelin1 Gene (EDN1) in a Cohort of Patients with Essential Left Ventricular Hypertrophy. Annals of Human Genetics, 71, 601-610. https://doi.org/10.1111/j.1469-1809.2007.00351.x

[11] Bella, J.N. and Goring, H.H. (2012) Genetic Epidemiology of Left Ventricular Hypertrophy. American Journal of Cardiovascular Disease, 2, 267-278.

[12] Arnett, D.K. (2000) Genetic Contributions to Left Ventricular Hypertrophy. Current Hypertension Reports, 2, 50-55. https://doi.org/10.1007/s11906-000-0058-3

[13] Kurbanova, D. and Eliseyeva, M. (2010) Genetic Background of Left Ventricular Hypertrophy in Uzbek Hypertensive Men. Turk Kardiyoloji Dernegi Arsivi, 38, 466-472.

[14] El-Shehaby, A.M., El-Khatib, M.M., Marzouk, S., et al. (2013) Relationship of BsmI Polymorphism of Vitamin D Receptor Gene with Left Ventricular Hypertrophy and Atherosclerosis in Hemodialysis Patients. Scandinavian Journal of Clinical and Laboratory Investigation, 73, 75-81. https://doi.org/10.3109/00365513.2012.743163

[15] Kaufman, B.D., Desai, M., Reddy, S., et al. (2008) Genomic Profiling of Left and Right Ventricular Hypertrophy in Congenital Heart Disease. Journal of Cardiac Failure, 14, 760-767. https://doi.org/10.1016/j.cardfail.2008.06.002

[16] Blazquez-Medela, A.M., Garcia-Ortiz, L., Gomez-Marcos, M.A., et al. (2012) Osteoprotegerin Is Associated with Cardiovascular Risk in Hypertension and/or Diabetes. European Journal of Clinical Investigation, 42, 548-556. https://doi.org/10.1111/j.1365-2362.2011.02619.x

[17] Noheria, A., Mosley, T.H. and Kullo, I.J. (2010) Association of Serum Osteoprotegerin with Left Ventricular Mass in African American Adults with Hypertension. American Journal of Hypertension, 23, 767-774. https://doi.org/10.1038/ajh.2010.59

[18] Omland, T., Drazner, M.H., Ueland, T., et al. (2007) Plasma Osteoprotegerin Levels in the General Population: Relation to Indices of Left Ventricular Structure and Function. Hypertension, 49, 1392-1398. https://doi.org/10.1161/HYPERTENSIONAHA.107.087742

[19] Morinaga, T., Nakagawa, N., Yasuda, H., et al. (1998) Cloning and Characterization of the Gene Encoding Human Osteoprotegerin/Osteoclastogenesis-Inhibitory Factor. European Journal of Biochemistry, 254, 685-691. https://doi.org/10.1046/j.1432-1327.1998.2540685.x

[20] Brandstrom, H., Stiger, F., Kahan, T., et al. (2004) A Single Nucleotide Polymorphism in the Promoter Region of the Osteoprotegerin Gene Is Related to Intima-Media Thickness of the Carotid Artery in Hypertensive Patients. The Swedish Irbesartan Left Ventricular Hypertrophy Investigation vs. Atenolol (SILVHIA). Blood Press, 13, 152-157. https://doi.org/10.1080/08037050410035563

[21] Brandstrom, H., Stiger, F., Lind, L., et al. (2002) A Single Nucleotide Polymorphism in the Promoter Region of the Human Gene for Osteoprotegerin Is Related to Vascular Morphology and Function. Biochemical and Biophysical Research Communications, 293, 13-17. https://doi.org/10.1016/S0006-291X(02)00137-7

[22] Mangena, P., Saban, S., Hlabyago, K., et al. (2016) An Approach to the Young Hypertensive Patient. SAMJ: South African Medical Journal, 106, 36-38. https://doi.org/10.7196/SAMJ.2016.v106i1.10329

[23] Moreno, M.U., Eiros, R., Gavira, J.J., et al. (2017) The Hypertensive Myocardium: From Microscopic Lesions to Clinical Complications and Outcomes. Medical Clinics, 101, 43-52. https://doi.org/10.1016/j.mcna.2016.08.002 
[24] Bastien, M., Poirier, P., Lemieux, I., et al. (2014) Overview of Epidemiology and Contribution of Obesity to Cardiovascular Disease. Progress in Cardiovascular Diseases, 56, 369-381. https://doi.org/10.1016/j.pcad.2013.10.016

[25] Arnett, D.K., Li, N., Tang, W., et al. (2009) Genome-Wide Association Study Identifies Single-Nucleotide Polymorphism in KCNB1 Associated with Left Ventricular Mass in Humans: The Hyper GEN Study. BMC Medical Genetics, 10, 43. https://doi.org/10.1186/1471-2350-10-43

[26] Yoshihara, T., Ishida, M., Kinomura, A., et al. (2004) XRCC3 Deficiency Results in a Defect in Recombination and Increased Endoreduplication in Human Cells. The EMBO Journal, 23, 670-680. https://doi.org/10.1038/sj.emboj.7600087

[27] Ariyandy, A., Sakai, C., Ishida, M., et al. (2018) XRCC3 Polymorphism Is Associated with Hypertension-Induced Left Ventricular Hypertrophy. Hypertension Research, 41, 426. https://doi.org/10.1038/s41440-018-0038-0

[28] Shen, A., Hou, X., Yang, D., et al. (2014) Role of Osteoprotegerin and Its Gene Polymorphisms in the Occurrence of Left Ventricular Hypertrophy in Essential Hypertensive Patients. Medicine, 93, e154.

https://doi.org/10.1097/MD.0000000000000154

[29] Bahramali, E., Rajabi, M., Jamshidi, J., et al. (2016) Association of ACE Gene D Polymorphism with Left Ventricular Hypertrophy in Patients with Diastolic Heart Failure: A Case-Control Study. BMJ Open, 6, e010282.

https://doi.org/10.1136/bmjopen-2015-010282

[30] Celczyńska, L., Horst, W., Bychowiec, B., et al. (2011) The Effects of Osteoprotegerin (OPG) Genepolymorphism in Patients with Ischaemic Heart Disease on the Morphology of Coronary Arteries and Bone Mineral Density. Kardiologia Polska (Polish Heart Journal), 69, 573-578.

[31] Choe, W.-S., Kim, H.-L., Han, J.-K., et al. (2012) Association between OPG, RANK and RANKL Gene Polymorphisms and Susceptibility to Acute Coronary Syndrome in Korean Population. Journal of Genetics, 91, 87-89. https://doi.org/10.1007/s12041-012-0131-0

[32] Lavie, C.J., Milani, R.V. and Ventura, H.O. (2009) Obesity and Cardiovascular Disease: Risk Factor, Paradox, and Impact of Weight Loss. Journal of the American College of Cardiology, 53, 1925-1932. https://doi.org/10.1016/j.jacc.2008.12.068 